Sarah Sweeney and Steven Buchanan

(C) 2018 by University of Chicago Press. Accepted for publication to Library Quarterly on 06/03/2018. The final published version is available at: https://doi.org/10.1086/697707 
Public libraries as cultural hubs in disadvantaged communities:

developing and fostering cultural competencies and connections 


\begin{abstract}
A cultural divide has been evidenced in the UK, with disadvantaged individuals and communities known to be least likely to participate in cultural activities. Recognising that low levels of cultural capital can present multiple barriers to cultural participation, and that public libraries have an important cultural role in supporting and promoting learning and development, this paper examines issues of cultural divide through the theoretical lens of cultural capital. Through analysis of examples of public library good practice in Europe, America, and the UK, this paper addresses an understudied topic, and advances our understanding of the sociocultural role of public libraries in stimulating cultural consumption, participation and engagement in disadvantaged communities. The paper also calls for further empirical research to evidence and operationalise cultural capital concepts in library practices.
\end{abstract}




\section{Public libraries as cultural hubs in disadvantaged communities: developing and fostering cultural competencies and connections}

Sarah Sweeney and Steven Buchanan

Public libraries have a widely-recognised role in supporting and promoting learning and development in the cultural context. As 'cultural hubs' they can 'connect communities and change lives' (Carnegie Trust UK 2014) by offering trusted spaces, for people to come together to access, share, create, appropriate and appreciate cultural resources and materials. In addition, public libraries facilitate the integration of culture into everyday life within and across communities through the provision of inclusive opportunities for collaboration, creativity, development, interaction, and enrichment. Cultural participation provides a mechanism for advancement and self-improvement (McMenemy 2009), in addition to improving health and wellbeing (Kim and Kim 2008, Leadbetter and O’Connor 2013, Carnegie Trust 2014), social cohesion (Jeannotte 2003) and neighbourhood regeneration (Bridge 2005). However recent social research in the UK (Warwick Commission 2015; Scottish Government 2016) has evidenced a cultural divide, with people from disadvantaged (e.g. employment, education, health) communities reported to be least likely to participate in cultural activities.

Low levels of cultural capital, understood as the cultural competencies which facilitate cultural participation and symbolise cultural capacity and authority, can present multiple barriers to cultural participation (Bourdieu 1984).

Individuals with low levels of cultural capital can lack not only the orientation towards and ability to participate in cultural activities, but also the belief that 
they are worthy of engagement (Savolainen 1995). In such circumstances public libraries have an important enabling role. For example, Anne Goulding (2008, 237) has argued that for public libraries 'facilitating cultural capital may be a means of addressing social exclusion, contributing to social capital and stimulating community engagement' and in so doing give 'an added dimension' to their cultural role within communities. However, to date there has been limited application of theories of cultural capital in the public library context. This paper seeks to better understand the sociocultural role of public libraries in addressing issues of cultural engagement, through a synthesis of public library cultural engagement practices across Europe, America, and the UK, examined through the lens of cultural capital,

\section{Cultural Capital}

Cultural Capital is a concept which originated within the broad theoretical oeuvre of noted sociologist Pierre Bourdieu, who sought to identify those 'social effects' which he believed lay at the root of 'the unequal scholastic achievement of children originating from the different social classes' (Bourdieu 1986, 106). Bourdieu believed that the education system reproduces rather than alleviates inequality, by privileging the cultural tastes and interests of the middle and upper classes (Bourdieu and Passeron 1977). Central to Bourdieu's argument is that the volume of social, economic, and cultural capital we possess determines our cultural tastes and dispositions. Therefore, for children from more affluent backgrounds, the privileged family habitus 'functions as a sort of advance' by encouraging an interest in and orientation towards 'legitimate' culture which the education system 'presupposes and 
completes' by recognises and rewarding within the curriculum (Bourdieu 1984, 59). Bourdieu argues that childhood domestic and scholastic acquisition of cultural capital, when combined with the right social 'connections' (Bourdieu 1984, 338), then facilitates preferential access to university places, employment opportunities and prestigious groups and organisations.

The domestic and scholastic acquisition of cultural capital (Bourdieu 1984, 69) discussed above, play complimentary but differing roles in enabling each of the three 'expressions' of cultural capital: embodied, objectified and institutionalised. Embodied cultural capital can be understood as the 'longlasting dispositions of the mind and body' towards a desire for cultivation and self-improvement (Bourdieu 1986, 106-107). Embodied cultural capital provides the relevant competence in the form of cultural skills such as knowledge, tastes and disposition which facilitate the appropriation of objectified cultural capital. Objectified cultural capital is commonly understood as a familiarity with and ability to appropriate both economically and symbolically (Bourdieu 1986, 109) objects of cultural significance such as books, paintings, and artefacts. The final expression of cultural capital, institutionalised cultural capital refers to the possession of academic qualifications which act as 'a certificate of cultural competence' (Bourdieu 1986, 109-110), not limited to the field of academia, but rather functioning more broadly as a 'trademark' of cultivation and accomplishment. (Bourdieu 1984, 58). 


\section{Social Inequality and Cultural Capital}

Bourdieu $(1999,4)$ believed that 'using material poverty as the sole measure of all suffering keeps us from seeing and understanding a whole side of the suffering characteristic of a social order'. The concept of cultural capital, which for Bourdieu forms part of the fabric of social life, provides a mechanism of highlighting the additional social and cultural factors which can result in inequality, particularly in disadvantaged circumstances. Bourdieu argued that the multi-dimensional nature of inequality could be evidenced through a reciprocal relationship with taste, which serves 'as a sort of social orientation, a "sense of one's place"" which guides individuals and groups 'towards the practices or goods which befit the occupants of that position' (Bourdieu 1984, 468-9). Essentially for Bourdieu our tastes, whether we like James Joyce or E.L James, Mozart or Madonna, are socially determined with much subsequent cultural capital research seeking to evidence a clustering of tastes, for high-brow or low-brow culture, along class lines. The social conditioning of cultural tastes, preferences and practices is significant as if the books we read or the cultural activities we participate in can be used as a mechanism of social classification (Jeannotte 2003, 38) then an individual's 'ability to enjoy or engage with cultural activities has a direct bearing on their place within society' (Goulding 2008, 235).

Cultural capital is created via the interactions between individuals, communities, activities, places, and objects and determinations of value attributed to these interactions are what defines culture as constituting a form of capital. In this sense, Bourdieu's (1984) use of the term 'distinction' can be seen as conveying a dual meaning- representing the power to both define the 
differences between and determine the quality of different forms of culture. Kate Oakley and Dave O'Brien $(2016,5)$ argue that cultural capital theory can be understood in terms of how 'differences in consumption patterns are linked to notions of value or worth', with a failure to consume or participate in 'legitimate culture' regarded as representing a 'deficit'. The argument that people can have 'the wrong values and attitudes' towards culture reinforces hierarchical levels of cultural value by legitimating what is perceived to be good and bad. Bourdieu argued that this represents a form of 'symbolic violence', which leads 'socially dominated' individuals, groups, and communities to 'devalue their own tastes, preferences, lifestyle capacities, or whole habitus' due to a socially conditioned need to revere 'dominant cultural forms and ways of being' (Prieur and Savage 2011, 570).

Contemporary realities of social and cultural stratification, are characterised by cultural behaviours as opposed to taste preferences (Bennett et al. 2010) with an increasingly omnivorous (Peterson 1992) attitude towards high and low brow culture forms evident amongst the middle and upper classes. A shift to an omnivorous disposition is consistent with the 'permanent revolution in tastes' predicted by Bourdieu $(1984,279)$. Rather than be considered as a departure from culture capital theory, arguably an omnivorous disposition can be understood 'a new way of expressing distinction' and a contemporary 'form of cultural capital' (Warde, Wright, and Gayo-Cal 2008, 150) which reflects the current social and cultural values of society. Meir Yaish and Tally Katz-Gerro $(2012,169)$ argue that a cultural divide can be understood in terms of cultural participation levels which serve as a contemporary 'public manifestation of social boundaries', with the line being 
drawn between those who participate and those who do not (Bennett et al. 2010, 252). This has been evidenced in recent social research in the UK which found that the 'wealthiest, better educated and least ethnically diverse' are 'the most culturally active' (Warwick Commission 2015, 33).

Bourdieu (1999, 127-128) argued that a low level of cultural capital has a negative impact on both the orientation towards and action of participating in cultural activities, which effectively 'chains one to a place'. The inability to engage in 'cosmopolitan' cultural activities out with familiar class and geographical confines, stems from 'schemes of perception and appreciation' that they are 'not for the likes of us' (Bourdieu 1984, 473). Helen Manchester and Emma Pett $(2015,224)$ found evidence of this in the contemporary cultural participation of young people, with those from affluent backgrounds displaying 'cosmopolitan cultural identities' in contrast to those from disadvantaged backgrounds who are 'positioned and position themselves as "out of place" ... in relation to certain, valued cultural places and activities'. As a result, low levels of cultural capital present multiple barriers to cultural development, with individuals lacking not only the orientation towards and ability to participate in cultural activities but also the belief that they are worthy of engagement (Savolainen 1995).

\section{Public Libraries and Cultural Capital}

Bourdieu's concept of cultural capital, by highlighting both the power of culture and the inequality which comes along with this, dovetails with both the purpose and the practice of public libraries. For Bourdieu $(1984,247)$ culture is a game, which favours those who are: orientated towards competing, aware 
of the rules and provided with the resources and skills necessary to compete. By their nature public libraries exist to level the playing field in the cultural context, offering opportunities for all to access and appreciate culture regardless of personal circumstances. Importantly, public libraries, by serving as 'sites for the production, dissemination, and appropriation of cultural capital' (Goulding 2008, 236), provide a third route, distinct from the traditional scholastic and domestic routes, to appropriate each of Bourdieu's three expressions of cultural capital: objectified, institutionalised, and embodied.

At a fundamental level, public libraries as a trusted community space where people can come together to access, share, and create cultural resources and materials, provide an optimal setting for the development of objectified cultural capital. Objectified cultural capital in the library context has been defined as 'access to libraries and their resources', which contain objects of ‘cultural significance’ (Ignatow et al. 2012). However, Anne Goulding (2008, 236) argues that in addition to the 'objectified cultural capital represented by their library collections' that public libraries provide individuals with the means to access collections via 'their organization and exploitation'. The 'exploitation' of library resources via reader development activities, provides a mechanism of enabling and empowering individuals to develop the cultural competencies required to fully engage with library collections. Cultural competencies are vital to appropriating objectified cultural capital, which does not represent a tangible quality within cultural objects, but rather the capacity to intellectually and aesthetically understand those objects. By touching on Bourdieu's (1986) distinction between economic and symbolic appropriation 
of cultural objects, Goulding (2008) highlights the key developmental role of public libraries in facilitating the accessibility of, rather than just providing access to, objectified cultural capital.

Arguments in support of the developmental role of public libraries date back to the enlightenment, which advocated the power of cultural activities as a means of advancement and self-improvement (McMenemy 2009). Contemporary public libraries continue this tradition by serving as 'rich literate environments' (UNESCO 2005) which enable and encourage learning and development in the cultural context. Through the provision of practical resources such as books, computers and quiet spaces for independent study, public libraries support the attainment of formal qualifications which constitute institutionalised cultural capital. In addition, public libraries play an important role in the provision of formal and informal lifelong learning opportunities, which are 'complimentary' to those offered by the education sector. (Ambition and Opportunity 2015). Bourdieu's $(1986,109)$ concept of 'academically sanctioned' institutionalised cultural capital does not sufficiently account for the multiple diverse routes towards personal, social, civic and employment development afforded by lifelong learning (European Commission 2003a) which for many people provides a more accessible and relevant method of learning. However, the nature of lifelong learning reflects a commitment to sustained development in the cultural context, which resonates with a personal desire for cultivation which facilitates the development of embodied cultural capital.

Embodied cultural capital constitutes 'slow efforts to improve the mind' achieved via participation in cultural activities, active engagement with 
cultural objects, and efforts to develop cultural knowledge (Bourdieu 1984, 495). The idea of embodying culture recognises that culture constitutes not just the 'works and practices which represent and sustain' our way of life but also a 'process of intellectual, spiritual and aesthetic development' (Williams 1983, 91). Public libraries enable the embodiment of culture by providing multiple diverse and inclusive entry points, which can generate cultural capital by acting as a catalyst for the development of knowledge, skill, taste and experience in a broad range of cultural forms and activities. For example, of pivotal importance in the digital age has been has been the public library role in fostering digital literacy by providing universal free access to digital resources and learning opportunities within communities. Digital literacy, is not only a core competency in contemporary society but also facilitates the development of embodied cultural capital by enabling the consumption and production of culture: from accessing events information online, engaging with interactive exhibits, downloading e-books, or creating images and sound.

\section{The cultural role of public libraries}

Public libraries have an important cultural role in communities, enabling 'Home-based', 'Going-out' and 'Identity-building' cultural practices (UNESCO 2014, 84): from the consumption of cultural products to an active participation in cultural activities and ultimately to sustained cultural engagement. For public libraries, facilitating cultural capital- understood as an everyday resource rather than a source of power (Pugh 2010) aligns with the inclusive ethos of this publicly funded cultural role, which endeavours to encourage both an appreciation for and empathy towards diverse forms of 
culture (Jones 1998, 137). Therefore, viewing the collections, resources, and services that public libraries provide through the theoretical lens of cultural capital, can increase understanding, awareness, and effectiveness of their contribution to stimulating cultural consumption, participation and engagement which serve as the mechanisms by which public libraries facilitate the generation of embodied, institutionalised and objectified cultural capital.

Cultural consumption, the private use of cultural objects which symbolise wider cultural tastes and preferences, and cultural participation, including both public involvement in cultural activities and attendance at cultural places or events, have traditionally been regarded as symbolising cultural capital (Bennett et al. 2010). Public libraries aid cultural consumption and participation by providing individual and collective opportunities to discover, discuss, and demystify objectified cultural capital. In addition, public libraries facilitate the embodiment of cultural capital, by going beyond offering opportunities to consume or participate in culture to enable engagement in the cultural context which is both 'purposive' and 'meaningful' (Susain 2016). Cultural engagement, the sustained cultural behaviours and practices which individuals and communities feel actively involved with and enriched by, represents cultural practices which are 'identity building' resonating with Bourdieu's concept of embodied cultural capital and its foundational role in the appropriation of objectified and institutionalised cultural capital. Public libraries can help individuals to embody culture by providing 'spontaneous, serendipitous and planned' (Spink and Cole 2006, 93) opportunities to engage with diverse cultural forms and in so doing bringing 
culture into the everyday lives of individuals by removing some of the barriers to generating cultural capital.

For public libraries developing approaches to making 'complex culture' (Usherwood 2007, 36) more accessible within communities, is an enduring challenge. Reijo Savolainen $(1995,261)$ has argued that issues of cognitive/cultural competence and the socio-cultural context which determines development and perceived value, serve as mutually reinforcing cognitive and affective barriers to the practice of everyday social and cultural participation. How we choose to spend our leisure time represents an adherence to the 'order of things' which provides a framework governing preferences appropriate to our 'way of life'. The newspapers we read, whether we frequent public libraries etc., constitute preferences and practices which are in fact not a choice, but rather a socially and culturally determined 'choice of the necessary' (Bourdieu 1984), given that individuals must 'always choose within the limits of their competence, which is built on social and cultural factors' (Savolainen 1995, 290). For public libraries, a focus on developing cultural competencies provides a mechanism for addressing both cognitive and affective barriers to library use, by improving the intellectual accessibility of resources and helping culturally disengaged communities to perceive library services as 'meaningful and worthy of engagement' (Savolainen 1995, 262).

Within library and information science literature, most notably in the work of Elfreda Chatman $(1996,1999,2000)$, the importance of issues of perception and norms in both constraining and enabling behaviour in disadvantaged and disengaged communities has been evidenced. How an individual perceives themselves, the world, and their place within it has a 
significant impact on determining 'those things that are important to pay attention to and those things that are not' (Chatman 1996, 194). Chatman's theory of situational relevance when applied to issues of library use can help to explain why public libraries can fail to register as a valid destination on the 'cognitive map that interprets the world' of culturally disengaged groups (Chatman 1999, 213). The perception that something such as cultural participation has 'little or no value to their lived experience' (Chatman 1996, 202), is aided by the absence of skholé (Bourdieu 1998), 'the disposition to invest oneself in activities that may seem wasteful to those who have not been liberated from urgency and necessity' (Robinson 2009, 504). Skholé constitutes a 'worldview' which both shapes and is shaped by social norms (Chatman 1999). Social norms orientate beliefs, aspirations, and behaviour in line with the worldview of a specific group or community and can provide a barrier to building cultural capital by limiting awareness of 'the cultural, educational and social norms that are fundamental to the greater social world' (Chatman 2001, 3).

\section{Public library cultural engagement practices}

Every day in communities around the world public libraries enable cultural consumption, participation, and engagement via the provision of cultural objects, interactions, activities, and opportunities. Book groups, story hours, literary festivals, creative writing classes, author talks are just some examples of the cultural activities regularly offered in public libraries which provide a mechanism for the development of cultural competencies. In addition, there are examples of public libraries developing innovative approaches to enrich 
existing experiences and reach new audiences in the cultural context. By reimagining 'the library as place and space' (Oliphant 2014, 358), contemporary public libraries remain a trusted place to engage in familiar cultural behaviours and practices whilst also providing a vibrant communitybased space within which new cultural experiences, not traditionally associated with libraries, can be provided. Examples of public library good practice distilled from initiatives explicitly promoting cultural engagement in Europe, America and the UK, place cultural capital in the library context by providing a starting point from which to identify how libraries stimulate cultural participation, enhance community engagement, and why this can generate cultural capital.

Demonstrating the role of public libraries in enriching disadvantaged communities through culture is the award winning 'Cultural Hubs' programme developed by St Helens Library Service. Despite its proximity to Liverpool, a former European City of Culture, St Helens is one of the most economically deprived and culturally disengaged areas in the UK. Improving the health and wellbeing of the community, particularly amongst young people and those with mental health issues is a key priority. Recognising that cultural participation can improve wellbeing, St Helens Library Service developed 'Cultural Hubs', a library facilitated diverse programme of cultural performances, activities and exhibitions designed to engage, involve and connect local communities with local culture by 'animating' library spaces. From poetry to plays, breakdance to book sculptures, crime solving to comedy stand-up, the diverse 'Cultural Hubs' programme aimed to not just make the library and its resources more accessible but crucially stimulate an interest in 
wider cultural participation. Innovative projects such as 'Cultural Hubs' highlight that by challenging 'people's perception of what a library is for' (Department for Culture, Media, and Sport 2015), perceptions about who libraries are for can also be challenged, generating benefits both for local communities and library services.

The impact evidenced from 'Cultural Hubs' demonstrates the need for cultural offers in public libraries which specifically target disadvantaged groups. By expanding and enriching their cultural offer to provide numerous, regular, and varied opportunities for everyday cultural appreciation and appropriation, St Helens Library Service expanded and enriched individual and collective cultural capital amongst the most culturally disengaged within the local community-families, young people and the mentally ill. This can be appreciated for example in increased local opportunities for cultural participation with one programme participant stating that 'A play like this would be something we would usually have to go to Liverpool or Manchester to see so it's amazing to have a quality production like this in my local library' (Department for Culture, Media, and Sport 2015). Whilst also for vulnerable library users, accessible sustained opportunities for cultural engagement had a meaningful impact on their wellbeing with one library user, who participated in a number of 'Cultural Hubs' programmes, stating that 'I had a longstanding alcohol problem. I didn't see a point in living. My real, active recovery started the day I came to the library' (Department for Culture, Media, and Sport 2015). In addition, further community and cultural engagement benefits were generated by designing and delivering programmes in 
collaboration and consultation with local artists and residents, which enabled a collective sense of investment in and ownership of the programme.

A recent national review by the Carnegie Trust (2014) evidences more broadly how UK public libraries can improve the wellbeing of communities by serving as 'cultural centres' which 'inspire' and 'enrich' through culture and the arts. Examples of good practice highlighted by the Carnegie Trust include: collaborations with creative professionals such as writers in residence in Northern Ireland and musicians in residence in Manchester; clubs which facilitate the development of cultural production skills amongst young people such as song writing in Yorkshire, stop frame animation in County Clare and Digital Toyboxes mobile makerspaces in Edinburgh; projects which challenge 'the misconception that libraries are just for books' by providing a community venue for performing plays in Glasgow, dance classes in Cheshire, and screening live performances in Suffolk. As highlighted by the Carnegie Trust (2014), public libraries across the UK are adopting diverse, vibrant, dynamic, and collaborative approaches in the cultural context to 'enrich the lives of individuals and communities'.

A further mechanism which is being utilised in the UK to facilitate cultural engagement is the development of strategic partnerships with creative agencies. Creative agencies can animate library spaces and services in diverse ways, tailoring approaches to specifically engage local communities. For example, library services in Blackpool and Lancashire both collaborated on distinct projects with La Petite Mort Dance Theatre Company. As part of Wordpool Blackpool Arts and Libraries Festival of Words, La Petite Mort 
dynamically used street stilt walking and vibrant costumes to 'bring the written word to life' whilst sharing 'sentiments and stories' out with the library space (La Petite Mort n.d.). Whilst in Lancashire, Accrington Library provided a non-conventional theatre space, alongside other venues in the community such as an old arts school and a university, within which to perform a collaborative dance piece 'Cabinet of Curiosity' created by La Petite Mort and local high school pupils (La Petite Mort n.d.). By working in collaboration with creative agencies, public libraries can stimulate wider cultural participation and provide a hub for cultural activity within communities.

In Lyon, France, a recognition of the provision of cultural events as a 'priority not the icing on a cake' for public library services has resulted in the development of a cultural policy, 'designed as an extension of collection policy' which consists of a series of city wide 'cultural actions' centred around a topic of local interest (Mackiewicz 2004, 2). Cultural actions such as workshops, performances, exhibitions, public talks, and meetings traditionally provide a mechanism for public libraries to engage with communities via the promotion of collections and resources. By theming cultural actions around a topic of local resonance such as 'A fabric of innovation' which addressed the industrial roots of the local area, Lyon public libraries could directly connect communities with both cultural content and context. In addition, the scale and variety of cultural actions available across the library network, which provided multiple routes to engagement, helped to maximise impact and 'enhance the capacity of the library to give access to knowledge' (Mackiewicz 2004, 3). 
In America, an increasing appreciation of the benefits of 'placemaking', a collaborative process of maximising both the impact and value of public spaces to strengthen 'the connection between people and the places they share' (Project for Public Spaces n.d.), has had an innovative impact on the cultural vitality of public libraries in several states. Project for Public Spaces (PPS) which provides a hub for training, resources, and best practice for placemaking projects argues that public libraries can become vibrant cultural destinations 'which matter' to communities by utilising a placemaking 'inside/outside’ approach. As an example, ImaginOn children’s library and theatre in Charlotte North Carolina which hosts an annual Wordplay Saturday event which 'brings stories to life' by providing 'performances inside the library and activities outside' transforming 'Charlotte into a giant party for kids' (Nikitin and Jackson, 2009). Another example in Frankfort Indiana, highlights how by adopting an inclusive understanding of cultural engagement "which is based on the philosophy "we can make our life a work of art"' (Smallwood 2013, 215), the library can become an everyday cultural hub of local life. By working with the community to develop and provide 'a broad range of activities emphasizing art, performance, and creativity' (Nikitin and Jackson, 2009), from piano lessons inside to gardening groups outside, the library provides the local community opportunities for collaboration, development, and enrichment.

In summary, public libraries, as evidenced by the synthesis of good practice distilled from the illustrative examples discussed above, provide numerous, regular, and varied opportunities for collaboration, creativity, development, interaction, and enrichment in the cultural context. Public 
libraries in Lyon France and St Helens England, involved and connected local communities with local culture by focusing on both cultural content and context. In Frankfort Indiana, a further emphasis on the local can be appreciated with the library promoted and recognised as an everyday cultural hub of local life. Public libraries in Blackpool England and Charlotte North Carolina, adopted vibrant and dynamic approaches to bring culture outwith the library space directly into the community, whereas public libraries in Lancashire and St Helens in England brought community created culture into the library space. Whilst, as highlighted, the holistic cultural role of public libraries can stimulate cultural consumption, participation, and engagement within communities and so generate cultural capital, there is a need however for the benefits of this cultural role to be empirically evidenced, particularly in disadvantaged communities. This process could be better achieved, understood, and advocated in library and information science by utilising and building on existing cultural capital research in other domains.

\section{Building on Existing Cultural Capital Research}

As identified in examples of public library good practice, whilst there may exist a wealth of material which demonstrates the generation of cultural capital by public libraries, there remains a need to define the concept in practice and identify the key indicators which demonstrate the impact of cultural capital. Authors such as Savolainen (1999, P18) have highlighted 'problems in the "translation" of Bourdieu's concepts into the vocabulary of LIS', as a result there are a lack of research studies which evidence: the library role in developing cultural competencies amongst disadvantaged groups; the key 
factors influencing intergroup behaviours within the public library context; and the extent to which cultural capital contributes to social inclusion and community engagement. However existing cultural capital research out with the library and information science domain, provides a useful starting point from which to better understand the public library role in enabling cultural consumption, participation, and engagement.

Cultural capital research which addresses reading habits and preferences, can be useful for public libraries in developing methods of generating cultural capital via the promotion of cultural consumption. Whilst studies which replicate research methods used by Bourdieu (1984), retaining unhelpful value distinctions between different genres and mediums of reading materials, may not sit comfortably with an inclusive contemporary public library ethos (Goulding 2008), their findings should still be of interest. For example, Tony Bennett, Mike Savage, Elizabeth Silva, Alan Warde, Modesto Gayo-Cal, and David Wright's $(2010,110)$ study of contemporary cultural practices in Britain, whilst evidencing a specific decline in book reading out with 'urban, educated and cosmopolitan populations', also found that amongst a representative sample of UK residents '98 per cent, are involved in some form of reading' (Bennett et al. 2010, 94). These findings present challenges and opportunities for public libraries to facilitate cultural capital utilising mechanisms of 'active intervention' (Opening the Book 1995) such as reader development programs. Focusing on the readers' response to books (Sullivan 2001), and the 'power' cultural objects can 'exert over agents through their meaningfulness" (Calhoun et al 1993, 33) as opposed to distinctions of inherent value, can encourage, enable, and empower readers by recognising 
the value of reading in all forms. For libraries, fostering a love of reading helps individuals to build cultural capital by aiding their personal development and ability to engage in wider cultural production and participation (Howard 2011).

Cultural participation can be a 'contributory agent for change... improving the quality of life of a person and his/her community' (Vermeersch and Vandenbroucke 2014, 54). Social research has evidenced the benefits of cultural participation both to the individual in terms of increased happiness and personal enrichment (Kim and Kim 2008) good health and satisfaction with life (Leadbetter and O'Connor 2013) and collectively within communities in relation to social cohesion (Jeannotte 2003) and neighbourhood regeneration (Bridge 2005). However, amongst socially excluded groups and those with low levels of education, cultural participation levels are low (Myerscough 2011; Leadbetter and O’Connor 2013; Scottish Government 2015). For community based cultural institutions like public libraries, theories of cultural capital can place participation data in context and aid the identification of appropriate intervention points to reach excluded groups. Of interest to public libraries should be research focusing on the influence of parental cultural capital on the cultural behaviours and practices of young people (Sullivan 2001; Nagel 2010; Willekens and Lievens 2014; Manchester and Pett 2015). By working with new parents with low levels of cultural capital to aid and promote development of the 'cultural and social competencies that are rooted in family upbringing' (Edgerton et al. 2012, 304), libraries can help to break the cycle of cultural disengagement amongst 
children not encouraged to participate in cultural activities (Scottish Government 2010).

Recent methods of facilitating cultural capital amongst disadvantaged groups within the education sector, provide two distinct approaches which could be utilised by public libraries in the planning and delivery of community engagement projects, which specifically involve cultural activities. In Scotland Donald Gillies, Alastair Wilson, Rebecca Soden, Shirley Gray, and Irene McQueen $(2010,30)$ examined the 'cultural intermediary' role of a school in an area of extreme deprivation in facilitating the development of the 'relevant' cultural capital needed to 'cope and succeed in a system which can be quite distinct' from the pupils' own culture. Whereas in the Unites States Kate Wegmann and Gary L. Bowen $(2009,7)$ evidenced how a school sought to 'build connections' with the local community by adopting an inclusive understanding of cultural capital which recognised and embraced 'the cultural strengths and assets that diverse families' can possess. Arguably the first method of facilitating cultural capital may seem more in line with the traditional role of libraries and librarians as cultural intermediaries (Goulding 2008), who both satisfy and shape the tastes of the communities they serve via the collections they 'legitimise' (Bouthillier 2000) by providing. However, approaching cultural capital generation from a deficit model perspective based on the 'externally perceived needs' (Overall 2009) of the community is at odds with the 'positive' and 'dynamic' relationships (Pateman and Vincent 2010) which contemporary libraries foster. Instead community engagement programmes, which 'inform', 'consult', 'involve', 'empower', 'stem from' 
and 'belong to' local communities (Sung 2012, 211), provide an inclusive model for enabling cultural engagement.

Examining public libraries through the lens of cultural capital could provide a useful tool for understanding relations between a number of issues of professional and wider societal concern, such as: a decline in library book lending (Breslin and McMenemy 2006) and contemporary reading habits (Bennett et al. 2010); engaging vulnerable families with library services (Goulding 2006) and cultural disengagement in the home (Edgerton, Roberts, and Peter 2013); developing collaborative alternatives to 'outreach' (Pateman and Vincent 2010) and the inclusive engagement approaches proving successful in other sectors (Wegman and Bowen 2009). However, a library and information science focused research agenda is needed which provides better understanding of the library role in developing cultural competencies amongst disadvantaged groups, the key factors influencing intergroup behaviours within the public library context, and the extent to which cultural capital contributes to social inclusion and community engagement. Operationalising the concept to enable the identification of public library specific indicators and benefits is of importance, as such indicators would provide empirical evidence of the key sociocultural role of public libraries, particularly in disadvantaged circumstances, and in so doing, might provide a mechanism of better evidencing and advocating the value of public libraries. Whilst this could prove a challenge given the fluid nature of cultural capital and entrenched difficulties in defining the concepts meaning and identifying its effects (Dumais 2002, 49), the ability to do so could be vital to the future of public libraries (Barker and Evans 2011, 8). 


\section{Conclusion}

Cultural capital forms part of the rich fabric of social life and can be a major form of social inequality, particularly in disadvantaged circumstances. Public libraries, by providing a vibrant, inclusive, and trusted community hub for people from all walks of life to come together to access, share, create, appropriate and appreciate cultural resources and materials, can alleviate inequality by enabling wider cultural consumption, participation, and engagement. As cultural intermediaries' libraries and librarians enable and encourage the development of knowledge, skill, taste and experience in the cultural context: from the consumption of cultural products to an active participation in cultural activities and ultimately to sustained cultural engagement. Although to date application of the concept of cultural capital within library and information science may be limited, generating cultural capital - the cultural competencies (e.g. knowledge, skills, and education) that facilitate cultural participation and symbolize cultural capacity and authority (Bourdieu 1984), arguably resonates with both the purpose and practice of public libraries.

For public libraries, facilitating the generation of cultural capital symbolises the developmental role of the library in helping individuals to not just access, but appropriate, appreciate and share culture. Adopting a broad, inclusive, and non-judgemental understanding of culture, facilitates the integration of cultural forms and activities into everyday life within and across communities. Examples of good practice in public libraries includes: directly connecting communities with both cultural content and context; promoting the library as both a trusted place to engage in familiar cultural behaviours and a 
vibrant space to experience new cultural forms; involving and connecting local communities with local culture; providing numerous, regular and varied opportunities for collaboration, creativity, development, interaction and enrichment; taking culture outside the library into the community and bringing community created culture into the library; and recognising and promoting the library as an everyday cultural hub of local life.

Viewing public libraries through the theoretical lens of cultural capital can help libraries to better define and advocate their role in developing and fostering cultural consumption, participation and engagement; and in particular, address issues of cultural divide through a better understanding of cognitive and affective barriers to participation. However, further research is arguably needed within the academic and professional library and information science community to operationalise the concept in practice. There is a need for further empirical studies evidencing: the library role in developing cultural competencies amongst disadvantaged groups; the key factors influencing cultural participation; and the extent to which cultural capital contributes to social inclusion and community engagement. Such a focused research agenda will advance our understanding of the important sociocultural role of public libraries, particularly in disadvantaged circumstances.

\section{Acknowledgments}

This research was funded by UK Art and Humanities Research Council Doctoral Studentship award XXXX in collaboration with Glasgow Life. 


\section{References}

Bennett, Tony, and Elizabeth Silva. 2011. "Introduction: Cultural capitalHistories, limits, prospects." Poetics 39 (6): 427-443.

Bennett, Tony, Mike Savage, Elizabeth Silva, Alan Warde, Modesto Gayo-

Cal, and David Wright. 2010. Culture, Class, Distinction. Abingdon:

Routledge.

Birdi, Briony, Kerry Wilson, and Joanne Cocker. 2008. "The public library, exclusion and empathy: a literature review." Library Review 57 (8): 576-592.

Bourdieu, Pierre. \& Jean-Claude Passeron. 1977. Reproduction in Education, Society and Culture. London: Sage. ( $2^{\text {nd }}$ ed. 1990)

Bourdieu, Pierre 1984. Distinction: A Social Critique of the Judgement of Taste. Abingdon: Routledge (2010 ed.)

Bourdieu, Pierre. 1986. “The Forms of Capital.” In: Hugh Lauder., Phillip Brown., Jo-Anne Dillabough., and A.H Halsey. Education, Globalization \& Social Change. Oxford University Press, 2006 pp. 105-118.

Pierre Bourdieu. 1998. Practical Reason: On the Theory of Action. Cambridge: Polity Press.

Bourdieu, Pierre. 1999. The Weight of the World: Social Suffering in Contemporary Society. California: Stanford University Press.

Bouthillier, France. 2000. “The Meaning of Service: Ambiguities and Dilemmas for Public Library Service Providers.” Library \& Information Science Research 22 (3): 243-272. 
Breslin, Frances, and David McMenemy. 2006 "The decline in book borrowing from Britain's public libraries: a small-scale Scottish study.” Library Review 55 (7): 414-42.

Bridge, Gary. 2006. "Perspectives on Cultural Capital and the Neighbourhood." Urban Studies 43 (4): 719-730.

Calhoun, Craig and Edward LiPuma and Moishe Postone. (eds) .1993. Bourdieu: Critical Perspectives. Cambridge: Polity Press.

Carnegie UK Trust. (2014). Speaking Volumes: The impact of libraries on wellbeing. Report Retrieved from:

http://www.carnegieuktrust.org.uk/carnegieuktrust/wpcontent/uploads/sites/64/2016/02/pub1455011469.pdf Data Set Retrieved from: http://www.carnegieuktrust.org.uk/carnegieuktrust/wpcontent/uploads/sites/64/2016/02/pub14550114671.pdf Last accessed: 11.02.2018

Chatman, Elfreda A. 1996. "The impoverished life-world of outsiders." Journal of the American Society for Information Science 47(3): 193-206.

Chatman, Elfreda A. 1999. "A Theory of Life in the Round." Journal of the American Society for Information Science 50 (3): 207-217.

Chatman, Elfreda A. 2001 "An Insider/Outsider Approach to Libraries, Change and Marginalized Populations." Keynote address presented at the national conference Alteration of Generations, Boras, Sweden, April 23-25, 2001. 
Department for Culture, Media \& Sport. 2015. "The art of the possible: libraries as creative hubs". Case Study. Retrieved from:

https://www.gov.uk/government/case-studies/the-art-of-the-possible-librariesas-creative-hubs . Last accessed: 11.02.2018

Edgerton, Jason D., Lance W. Roberts, and Tracey Peter. 2013. "Disparities in Academic Achievement: Assessing the Role of Habitus and Practice." An International and Interdisciplinary Journal for Quality-of-Life Measurement 114(2): 303-322.

Frederiksen, Lia. 2015. "Our Public Library: Social Reproduction and urban public space in Toronto.” Women's Studies International Forum 48: 141-153.

Gillies, Donald, Alastair Wilson, Rebecca Soden, Shirley Gray, and Irene McQueen. 2010. "Capital, Culture and Community: Understanding School Engagement in a Challenging Context." Improving Schools 13(1): 21-38.

Goulding, Anne. 2004. "Libraries and Social Capital.” Journal of Librarianship and Information Science 36(1): 3-6.

Goulding, Anne. 2006. Public Libraries in the $21^{\text {st }}$ Century: Defining Services and Debating the Future. Aldershot: Ashgate.

Goulding, Anne. 2008. "Libraries and cultural capital.” Journal of Librarianship and Information Science 40(4): 235-237.

Howard, Vivian. 2011. "The importance of pleasure reading in the lives of young teens: Self-identification, self-construction, and self-awareness.” Journal of Librarianship and Information Science 43(1): 46-55. 
Ignatow, Gabriel, Sarah M. Webb, Michelle Poulin, Ramesh Parajuli, Peter Fleming, Shika Batra, and Diptee Neupane. 2012. "Public Libraries and Democratization in Three Developing Countries: Exploring the Role of Social Capital." Libri 62 (1): 67-80.

Jeannotte, M. Sharon. 2003. "Singing alone? The contribution of cultural capital to social cohesion and sustainable communities" The International Journal of Cultural Policy 9 (1): 35-49.

Johnson, Catherine A. 2010. "Do public libraries contribute to social capital?: A preliminary investigation into the relationship." Library \& information science research 32(2): 147-155.

Jones, Bonna. 1998. "Customers are consumers of library resources and services- or are they?" The Australian Library Journal 47(2): 131-144.

La Petite Mort (ND). Performance Work- Cabinet of Curiosities: Retrieved from: http://www.lpmdancetheatre.com/cabinet-of-curiosities . Last accessed: 11.02.2018 Wordpool: Retrieved from:

http://www.lpmdancetheatre.com/wordpool . Last accessed: 11.02.2018

Leadbetter, Clare. and Niamh O'Connor. 2013. "Healthy Attendance? The impact of cultural engagement and sports participation on health and satisfaction with life in Scotland" Scottish Government Social Research. Retrieved from: http://www.gov.scot/Resource/0043/00430649.pdf Last accessed: 11.02 .2018 Mackiewicz, Etienne. 2004. "Programming cultural events in a network of libraries." Paper presented at: IFLA WLIC 2014 - Lyon - Libraries, Citizens, Societies: Confluence for Knowledge in Session 203 - Metropolitan Libraries. 
In: IFLA WLIC 2014, 16-22 August 2014, Lyon, France. Retrieved from: http://library.ifla.org/874/ Last accessed 11.02.2018

Manchester, Helen and Emma Pett. 2015 "Teenage Kicks: Exploring cultural value from a youth perspective." Cultural Trends 24(3): 223-231.

Marcella, Rita and Graeme Baxter. 2000. “The impact of social class and status on citizenship information need: the results of two national surveys in the UK." Journal of Information Science, 26 (4): 239-254.

McMenemy, David. 2009. The Public Library. London: Facet Publishing. Myerscough, John. 2011. Glasgow Cultural Statistics Digest: A Digest of Cultural Statistics. Retrieved from:

http://www.understandingglasgow.com/assets/0000/5013/Cultural_Statistics 1_Feb_pdf_2_.pdf Last accessed: 11.02.2018

Nagel, Ineke. 2010. "Cultural Participation Between the Ages of 14 and 24: Intergenerational Transmission or Cultural Mobility?” European Sociological Review 26(5): 541-556.

Nikitin, Cynthia. and Jackson, Josh. 2009. "Libraries that Matter: Project for Public Spaces.” Retrieved from:

http://www.pps.org/reference/librariesthatmatter-2/ . Last accessed: 11.02.2018

Oakley, Kate. and Dave O'Brien. 2016. "Learning to labour unequally: understanding the relationship between cultural production, cultural consumption and inequality". Social Identities 22(15): 471-486 
Oliphant, Tami. 2014. "I'm a Library Hugger!: Public Libraries as Valued

Community Assets.” Public Library Quarterly 33 (4): 348-361

Opening the Book. 1995. "Branching Out." Retrieved from:

http://www.openingthebook.com/archive/branching-out/page2.asp?idno=519 .

Last accessed: 19.10.2016

Overall, Patricia Montiel. 2009. “Cultural Competence: A conceptual

Framework for Library and Information Science Professionals.” The Library

Quarterly 79 (2): 175-204

Pateman, John. and Vincent, John. 2010. Public Libraries and Social Justice.

Abingdon: Ashgate.

Prieur, Annick. and Savage, Mike. 2011. "Updating Cultural Capital Theory:

A discussion based on studies in Denmark and in Britain." Poetics 39 (1): 566580.

Project for Public Spaces (ND). What is placemaking?. Retrieved from:

http://www.pps.org/reference/what_is_placemaking/ Last accessed:

\subsubsection{8}

Pugh, Allison J. 2011. "Distinction, boundaries or bridges?: Children, inequality and the uses of consumer culture." Poetics 39(1): 1-18.

Rankin, Carolynn. and Avril Brock. 2012. Library Services for Children and Young People: Challenges and opportunities in the digital age. London: Facet Publishing.

Robinson, Laura. 2009. “A TASTE FOR THE NECESSARY.” Information, Communication \& Society 12(4): 488-507. 
Savolainen, Reijo. 1995. "Everyday Life Information Seeking: Approaching Information Seeking in the Context of "Way of Life"." Library and Information Science Research 17 (3): 259-294.

Savolainen, Reijo. 1999. “Academic Capital and Information Seeking Career" Swedish Library Research 3: 5-19.

The Scottish Government. (2010). Child's Play: The links between childhood encouragement and adult engagement in arts and culture. Evidence from the Scottish Household Survey Culture Module 2007/8. Retrieved from: http://dera.ioe.ac.uk/2187/1/0109571.pdf . Last accessed: 11.02.2018 The Scottish Government. 2016. Scotland's People Annual Report: Results from the 2015 Scottish Household Survey: Retrieved from: https://beta.gov.scot/publications/scotlands-people-results-2015-scottishhousehold-survey/documents/00506173.pdf?inline=true. Last accessed: 11.02.2017

Smallwood, Carol. 2013. Bringing the Arts into the Library. Chicago: ALA Editions.

Spink, Amanda. And Charles Cole. 2006. New Directions in Human Information Behaviour. Dordrecht: Springer.

Sung, Hui-Yun., Mark Hepworth and Gillian Ragsdell. 2012. "Investigating essential elements of community engagement in public libraries: An exploratory qualitative study." Journal of Librarianship and Information Science 45(3): 206-218. 
Sullivan, Alice. 2001 "Cultural Capital and Educational Attainment." Sociology 35(4): 893-912.

UNESCO. 2005. "Education for all: Literacy for Life.” Global Monitoring Report. Retrieved from:

http://unesdoc.unesco.org/images/0014/001416/141639e.pdf . Last accessed: 11.02 .2018

UNESCO. 2014. "The UNESCO Culture for Development Indicators:

Methodology Manual.” Retrieved from:

http://en.unesco.org/creativity/sites/creativity/files/digitallibrary/CDIS\%20Methodology\%20Manual_0.pdf . Last accessed: 11.02.2018 Usherwood, Bob. 2007. Equity and Excellence in the Public Library. Aldershot: Ashgate.

Van De Werfhorst, Herman G. 2010. "Cultural capital: strengths, weaknesses and two advancements." British Journal of Sociology of Education 31(2): 157169.

Vårheim, Andreas. 2011. “Gracious space: Library programming strategies towards immigrants as tools in the creation of social capital." Library \& Information Science Research, 33(1): 12-18.

Vermeersch, Lode. and Vandenbroucke, Anneloes. 2014. "Is social, cultural and recreational participation a luxury for people living in poverty? An analysis of policy intentions and measures." Journal of Social Intervention: Theory and Practice 23 (1): 53-71 
Warde, Alan. 2008. "Dimensions of a social theory of taste." Journal of Cultural Economy 1(3): 321-336.

Warde, Alan, David Wright and Modesto Gayo-Cal. 2008. "The omnivorous orientation in the UK." Poetics 36 (2-3): 148-165.

Warwick Commission. 2015. "Enriching Britain: Culture, Creativity \& Growth: The 2015 Report by the Warwick Commission on the Future of Cultural Value.” University of Warwick. Retrieved from:

http://www2.warwick.ac.uk/research/warwickcommission/futureculture/finalr eport/warwick_commission_report_2015.pdf . Last accessed: 11.02.2018

Wegmann, Kate, and Gary L. Bowen. 2010. "Strengthening Connections between Schools and Diverse Families: A Cultural Capital Perspective.” The Prevention Researcher 17 (3): 7-10.

Willekens, Mart. and John Lievens. 2014. "Family (and) culture: The effect of cultural capital within the family on the cultural participation of adolescents." Poetics 42: 98-113.

Williams, Raymond. 1988. Keywords: A vocabulary of culture and society. London: Fontana Press.

Winkle-Wagner, Rachelle. 2010 "Cultural Capital: The Promises and Pitfalls in Education Research." ASHE Higher Education Report 36(1): 1-144.

Yaish, Meir and Tally Katz-Gerro. 2010. "Disentangling 'Cultural Capital': The Consequences of Cultural and Economic Resources for Taste and Participation." European Sociological Review 28(2): 169-185. 
Sarah Sweeney: [PhD Student], Department of Computer and Information Sciences, University of Strathclyde, Glasgow, UK. [Is a chartered librarian with over a decade of experience working in UK public and school libraries. She is currently completing a $\mathrm{PhD}$, funded by the UK Arts \& Humanities Research Council, examining the cultural intermediary role of public libraries within disadvantaged communities. Her research brings together theories of cultural capital with theories of information behaviour to identify the various mechanisms by which public libraries develop cultural competencies and stimulate cultural consumption, participation and engagement.] Email: sarah.sweeney@strath.ac.uk.

Steven Buchanan: [Reader], Department of Computer and Information Sciences, University of Strathclyde, Glasgow, UK. [Reader and Head of Human Information Behaviour Research within the Department of Computer and Information Sciences, University of Strathclyde. With a particular interest in Information Behaviour at both the organisational and individual level, research interests and expertise encompass organisational and human information behaviours. He has undertaken a number of studies investigating human information behaviours in marginalised and/or disadvantaged circumstances including a major information poverty study exploring how public libraries and other information providers spanning health, social care, and education can support young first time mothers from areas of multiple deprivations and their children to prosper in the digital age.] Email: [steven.buchanan@strath.ac.uk]. 